\title{
SYNTHESIS AS CONCEPTION SHIFTING
}

\section{Statement of Contribution}

There seems to be some confusion about the distinction between analysis, systems and synthesis. This paper contributes by to the OR problem solving community by explaining synthesis. It explains what it is and its role in interpreting messy situations. Synthesis identifies problems for analysts to work on, it is a process of generating alternative analogies, interpretations or perspectives, akin to but preferable to metaphoric analysis. It is about generating alternative conceptions of messes. Much of the paper reports two case studies which demonstrate re-conceptualisation, how it occurred and how it totally changed the language, attitude and subsequent problems seen to be in need of solution. The paper is important to OR analysts because it reminds them that their analysis is often built on an assumed somewhat abstract one conception of the mess they are assisting to dissolve.

Authors:

*Luke Houghton

Griffith Business School,

Griffith University,

Brisbane, Australia

l.houghton@griffith.edu.au

Mike Metcalfe

School of Management

University of South Australia

Adelaide, 5001

mike.metcalfe@unisa.edu.au 


\title{
SYNTHESIS AS CONCEPTION SHIFTING
}

\begin{abstract}
John Dewey's work inspired Simon, Churchman and Ackoff. To encourage rigorous thinking, Dewey makes the rallying cry: Synthesise don't just analyse. Operational research does analysis well. However, our understanding of its conjoint twin, synthesis, may need some more pragmatic rationalisation. Synthesis, often confused with systems thinking, is thought to be a process of engagement with alternative conceptions (interpretations) of the problem domain; conceptions that suggest a different solution set. Therefore, this paper explores the proposition that operational research needs to engage more synthesis to complement its skill at analysis. Why synthesis is required, what it is and how it works is explained. Two case studies are provided to demonstrate the mechanisms of synthesis as one part of strategic thinking.
\end{abstract}

Keywords: Synthesis, systems thinking, shifting concepts, case studies. 


\section{SYNTHESIS AS CONCEPTION SHIFTING}

\section{Introduction}

Interpreting what Ackoff calls 'messes' is problematic. When not done creatively a messy situation can be reduced to a wrongly conceptualised problem (Ackoff, 1994). Dooley uses the mushroom rhizome to explain messes because they only reveal their reproductive organs above ground (1999,p.3). "... a lot like a mushroom: there is usually a great deal more to it than you can see, and the part that gives it its true scope and strength to persist is often out of sight. However, this does not communicate the dynamic nature of how interpreting messes involves differing re-conceptions. Checkland (1981) argues that messes, which he calls swampy problems, are defined by those who conceive them. Analysts often only provide one thesis or conception of the problem relevant to one moment in time (Churchman 1968). Analysts often have to use their own conception as they attempt to assume some kind of abstract customer whom they "concoct out of a multitude of conflicting interests." This may not reflect the conceptions being used by those who have to wear any solution. The process of identifying and working with messes, as multiple conceptions intertwined, is understanding that these multiple conceptions are in a state of an everchanging flux. They cannot be nailed down for too long because they constantly evolve as perceptions do.

Sless (1986) uses the shifting-landscape metaphor. Synthetic thinking is appreciating that thinking about messes is like groups of people walking through a landscape able to communicate but not able see each other. They are trying to arrange to meet in a common distant place but the act of communication makes the landscape change. Karl Marx used the caterpillar metaphor. Caterpillars cannot be understood without knowing about the butterfly. Analysis, cutting the caterpillar up into parts, is only of limited use. An attempt to interpret messes by extracting variables is like cutting up the caterpillar to understand life or evolution. It needs to be understood as part of a process, an element in larger, more complex systems. Others (O'Loughlin and McFadzean 1999; McFadzean and Money 1994) use the flux metaphor. They argue that the act of interpreting messes needs careful handling, because of uniqueness, context and the changing flux of messy problem situations. Any solution needs to be flexible enough to handle both the flux in the mess and in its context.

Stacey $(1996,2003)$ therefore argues that methods designed for controlling difficult situations typically underestimate the complexity between stakeholder arrangement. Learning takes place in the context of the interconnectedness of peoples' ideas, as part of complex social environment. Any attempts to reduce this complexity may result in problems 
in other parts of the problem situation. This was observed in the research of Tucker, Edmonson and Spear (2002). They studied workers in a hospital for 197 hours, discovering a recurring pattern. The researchers were surprised to note that the problem solving efforts of managers actually hindered later organisational development, because the issues that employees dealt with on a daily basis were connected to bigger issues. The bigger 'organisational' level of learning was hindered because smaller day to day decisions, impacted and affected strategic problems.

Stacey rejects the idea that it is possible to control how messes are thought about via any formal process or methodology because of his stance of the social order of things as being chaotic. That is, control is an illusion created by reductionist thinking (Stacey 2001). Liebl (2002) argues that messes are community problems (group-based) and behave like multiple moving targets that once defined are re-defined by shifting internal politics and so escape easy definition. "It is because of this political dimension that societal problems can be regarded as issues that represent moving targets both in terms of content and mobilization."

According to these researchers, and others, (Ulrich 2003; Wheatley 2001), there is a need for more than the normally very productive science of "picking to pieces" analysis (Dewey, 1910). Synthetic thinking as a supportive, conjoint paradigm to assist analysis, one aligned more with the pluralism of the continental and pragmatic philosophers, is also required.

This paper explores the proposition that "mess interpretation" needs to include a process of seeking alternative conceptions of the mess, a process of synthesis. Synthesis is not seen to be about just zooming-out on a situation, more wholeness, or the inclusion of more elements. These are systems thinking, which needs both analysis and synthesis. Synthesis is about analogy, re-conceptualising the mess. To justify this, this paper will now discuss the role of synthesis. Later two case studies are provided to demonstrate the mechanisms of synthesis as one part of interpreting messes.

\section{Synthesis}

Simon's work on the rational analysis of problems (March \& Simon 1958; and Newell \& Simon 1972) won him a Nobel Prize at a time when artificial intelligence was an exciting new discipline. The popularity of the mathematician Polya (1962:1965) reinforced Simon's approach which was based on his interest in how to design chess playing software. It became the scientific problem solving method (Polya, 1965 and Simon, 1996) of the day. A problem is a 'thing to be solved' or fixed (Checkland 1999; Landry 1995) by first identifying the full set of rational solutions. This forms the basis of the somewhat unfortunate decision 
making staircase, sadly still in the mainstream theory on how to solve social problems. This confuses how computers make decisions with how humans do. For example, it assumes away the issue of how the problem was conceptualised in the first place. This by-pass of the conceptualising step is misdirecting because the analysts attention quickly becomes fixated on the astronomical demands identifying all relevant information and possible solutions. This forces the introduction of bounded rationality. That is, the analyst is limited to making optimal decisions because they have a lack of information or information processing capacity (Simon 2000). They satisfice or reach a solution that is imperfect; computers are needed to overcome the imperfections of people. However, bounded rationality is a compromise to assuming that the analyst can ignore the dynamic and chaotic nature of the re-conception of the original messy situation possible. Use of the language, 'first define the problem' should perhaps be 'last define the problems that arise from your conception of the mess'.

The epistemology underlying the non conceptualise view of problem solving is reflected in March's (1978:1988) argument that "intelligence" in decision making is an effort to rationalise anomalies or weaknesses in human behaviour under conditions of ambiguity. Emotions and prior conceptions are a weakness. The rationality that he and others (eg. Simon, 1997) argue for is based on the idea that all problem solving activity and subsequent decision making must be a matter of logical analysis or reasoning.

To the best of our current knowledge, the underlying processes used to solve illdefined problems are not different from those used to solve well defined problems. Sometimes it is argued, to the contrary, that solving ill-defined problems involve processes that are 'intuitive', 'judgmental', or even 'creative' and that such processes are fundamentally different from the run-of-the-mill, routine, logical, or analytical processes employed in well-structured problem-solving. (Simon 1997:128)

The pragmatists (Peirce, 1878; Menand, 2001) agree that rationality is essential but our reasoning depends on our prior conceptions of the problem situation. It is not a matter of reasoning versus judgement or emotional intuition. Rather what prior conceptions are driving the differing reasoning of conflicting parties? Some hint of this can be seen in basic logic statements:

All platypus are mammals,

All mammals do not lay eggs,

Therefore, all platypus do not lay eggs. 
This is deductively valid. We know however, the conclusion is wrong because the mammal premise is wrong. The prior conception of "what is a mammal" needs to be revised. Reasoning depends on prior conceptions.

Chia (1996), much like Landry (1995) recognises the seminal work of March and Simon, arguing that, while genuine insights were gained, their work did not go far enough in exploring the epistemological issues related to their interpretation of problem solving. Simon (1960) displays his chess programming objectivist epistemology when he argues that problems are gaps between what is desired and the present reality. Although he undermines this a little in his later book The Science of the Artificial (Simon, 1996). In the objectivist stance, problems are like physical objects; they physically exist and can be reached. Problem solving then becomes open to the analysis tools to reduce that gap between desire and present reality. This realist, positivist, epistemology may be more useful for the physical sciences. A pluralist interpretive epistemology may be preferable for interpreting messes (Franco, 2006). This focuses on the possible prior conceptions usually brought by differing stakeholders. It is thought that interpreting messes is better thought of as a process of constantly redefining, re-conceptualising the mess. Analysis, while useful in its own right, can also serve to help with those re-conceptions.

Dewey (1910) uses the rallying cry, "Don't just analyse, synthesise". Time has been a little cruel to the word as an adjective, synthetic thinking. For many modern readers synthetic refers to man made materials. Dewey was thinking of synthesis as in thesis, antithesis and synthesis; a creative outcome of rationality. In the passing century the term 'analyse' has become synonymous with thinking. Dewey sees 'analyse' as reductionism, looking inwardly at the problem not outwardly, dividing the problem into elements (variables) and studying these separately. He uses the term 'picking apart'. This is the preferred approach of rational analysis. By synthesise, looking outwardly, as a pragmatist he appears to mean drawing of different conceptions of the problem domain, to see the problem from differing perspectives. He uses the historic example of the suction water-pumps. Mines were limited to certain depth because suction pumps strangely could only pump water out to a particular height. Analysis meant looking at the details of the water, pumps and vacuums more carefully. Synthesis means looking for different conceptions of vacuums beyond its acting to pulling the water up pipes. Dewey argues that synthetic thinking about analogous water surfaces led to the re-conception that the vacuum was merely removing a restriction on atmospheric pressure from pushing water up the pump tubes. This was how atmospheric pressure was 
discovered. Synthesis therefore suggests engaging with different conceptions of a situation, which in turn suggest different solution sets.

\section{Alternative Conceptions}

The mess that is the war in Iraqi has been conceptualised (defined) in many different ways. It is a military issue, an oil issue, a civil war, a commercial opportunity, new colonialism, liberation, and many more. These conceptions are dynamic, plural, dialectical and chaotic. The suggestion that the Iraqi mess be solved by first defining the problem, simply begs the question, which problem. Each problem is a particular interpretation, resulting from which conception, that will suggest differing solution sets. Deciding which, and whose, conceptions of the mess ought to be used is the problem. Once a conception has been agreed, the solution becomes almost obvious. In Iraq, if the war is conceptualised as providing democratic freedom then the solution is obvious, stay and fight radicals. If Iraq is defined as an imperial invasion to secure oil supplies, then the solution is also obvious. The Americans should leave.

James and Dewey (see Mitroff, 2004) argue that rigorous thinking includes making explicit the conceptions we're using to make sense of things that occur around us. A failure to do so means we will use undisclosed conceptions. The term sense-making has been used to refer to this process of constructing numerous different conceptions to interpret what goes on around us (Weick 1995:2001; Franco 2006). Rosenhead (1996) seems to be using the term structuring in the same way. Argyris' (Argyris and Schon,1996) term 'theory in use' also seems to be referring to the default or actual conception being used to interpret a situation. It is contrasted with 'espoused theory' which is the conception that pretended to be used. Some conceptions we use to sense-make the world may be genetic like warmth, survival empathy and reproduction. Others are learnt in childhood like work, respect, independence and fun. These often become default conceptions. Others are learnt as part of becoming a professional like objectivity, respect, profit, and measurement. Interpreting messes therefore becomes a matter of first appreciating what conceptions are being used even if by default. Next the conceptions wanted to be used are made explicit. This is similar to setting up criteria for evaluation.

Gilbert (1991) makes the case that we have to conceptualise regardless of whether we are aware of it or not. "...as perception construes objects, so cognition construes ideas". He draws on experimental psychology findings, to compare Descartes' thoughts on how we move from a conception to a belief, with those of Spinoza, opting for Spinoza. Descartes suggests we appreciate sensations received by the brain in a neutral form and then later 
conceptualise those sensations into a belief. Spinoza suggests that we use conceptions to interpret sensations, so understanding sensation is synonymous with believing it. We have to actively then set about a process of critiquing this belief if we are to later disbelieve it. The evidence Gilbert provides to support his argument is quite extensive, including noting that children have to be taught to be disbelieving, and that our language defaults to belief, it takes more words to state something in the negative. He reviews the psychology literature on people making decisions when stressed. Their default position is to act as if anything they have been told was correct. Moreover, subjects told that the information they were being given was false, when stressed, used it as if they believed it. This all aligns with the human information processing research which shows a general failure of people to seek disconfirming evidence as part of their inquiry strategies. This line of reasoning explains, at the cognitive level, how conceiving a problem is believing it to exist, how it is conceived will influence what and how it is believed. How we believe something is likely to affect our view of the appropriate solution (see rule $9 b$ in Rittel and Webber, 1973 for example).

It appears to be the unique role of human beings to shape, define and 'appreciate' problems from their own mental constructions of the world (Vickers 1983). Vickers sees the world as mysterious and unable to be understood through anything except the way in which we structure our interpretations of it (Checkland, 2005). For actors to perceive a situation to be of concern, the mental constructs they use to evaluate it must inform them of this particular view. As the multiple conceptions engage and intertwine resulting in multiple cognitive facilities at work in assessing the problem, different views begin to surface that might also be seen as relevant to the problem situation.

Klein (1989) observed the actions of experienced fire-fighters, nurses, data programmers, soldiers, paramedics and design engineers. He describes their problem solving as 'recognition primed', they appeared to observe the problem domain until they recognised a pattern. Firemen recognised a particular colour of flames in certain locations. They then knew how to respond. The task was one of situation assessment not option selection. He found that once an option was apparent, $96 \%$ of the time experts did not attempt to generate more options in order to make comparisons. Rather they moved on to thinking through if their conjectured solution would work, or how it would have to be modified to work. Problem solving was not a comparison of alternatives but rather a process of editing their first thought conjectures. This is what Dewey (1910) described as reflection. Klein's work raises the issue of training people to use particular conceptions. Being a professional like a lawyer or doctor can be seen as being training in a particular conception of the world. For the military and emergency services, training people into using particular conceptions in response to threatening situations, takes on considerable importance. Educating them to be open to 
alternative conceptions, to be able to shift conceptions, may also be important. Weick (1993) uses the example of fire fighters who parachuted into a forest fire perishing because they locked into one default conception of the shape of a fire front.

\section{Conception Shifting}

It is being argued that interpreting messes is not only about analysis but also involves an engagement with alternative conceptions, synthesis. The above discussion raises the question of where creative conceptions might come from. Systems for thinking about conception shifting (reframing) have been specifically developed. Four of these will be outlined below. However, conception shifting needs to be thought of a creative act, requiring an intuitive leap. The four alternatives therefore need to be thought of as merely illustrative of how to set about encouraging novel, but useful conceptions.

\section{Metaphors}

In the introduction of this paper metaphors were used to generate alternative conceptions of messes. New metaphors appear to offer new concepts. The classic example is Morgan's (1997) organisational metaphors. He uses the language of (p.6) their providing '...fresh ways of seeing, understanding and shaping the situations that we want to organise and manage'. He also uses the term 'competing insights'. So using his organisational metaphors, a supply chain failure can be seen to be like a broken machine, an organism failing to adapt, a brain demented, or prison camp breakout and so on. Schon (1963) however, distinguishes between metaphors and conceptions but agrees metaphors can be turned into conceptions. Metaphors produce images, conceptions cannot be imagined, only examples can. The machine metaphors can become a mechanistic or automated conception of supply chains.

\section{Systems Shifting}

A very powerful conception shifting tool is that of systems thinking (Ackoff 2000). First, it shifts conceptions from the problem being an object to being an element in one of any number of systems. A plane crash can be seen as an aviation system failure, a meteorology system failure, a cockpit instrumentation system failure or a human pulmonary system failure. Not only is zooming in and out useful as a means of generating new systems conceptions, but so is combining elements in the system. Putting the elements of the pilot and runway together, it is quick to imagine another system, the airport approach design system. These systems can be investigated using the systems sub concepts of boundary, transformation and so on. What is the systems boundary, what does it transform? 


\section{Contradiction}

It is possible to see the world, not as an ordered hierarchy, but rather as everything being in tension, contradictory, or ironic. Contraction is a process of holding two competing insights against each other to take advantage of their interplay; exploring their creative tension (Schultz and Hatch 1996). The intent is to produce a synthetic, a third way of seeing. Karl Marx used the now famous example of placing the workers' intellectual property over production in tension with the wealth of the aristocracy. In the Iraq example used earlier, the conceptions of freedom fighter and imperialist invader might be set up in contradiction. The intent is to use this contradiction as a process to facilitate a creative synthesis, a new conception. Through appreciating the similarities and differences simultaneously, hopefully, a new richer conception can be sought (Chanin \& Shapiro 1985; Grint 2003). When this synthesis conception is found, the solutions it suggests will satisfy supporters of either of the initial conceptions.

\section{Engagement}

Clearly, one of the most obvious means of appreciating alternative possible conceptions is through engagement with people from diverse backgrounds, or at least with their ideas. This engagement might simply be of the form of being surprised by their interpretation of the mess. There is now an extensive education, politics, sociology and psychology literature that explores 'engagement' to describe the cognitive, collective, intellectual and emotional involvement of people in some purposeful identification of their differing concerns (Houghton, 2008). In the majority of the management literature, the term engagement is used as in the Merriam-Webster dictionary, to mean emotional involvement or commitment. Cognitive engagement is assumed to include emotional engagement, as both appear to affect behaviours. Engagement is seen as a way of learning from stakeholders who present with conflicting interpretations of a problem and its possible solutions. In this context, Ledington and Ledington (2001) define engagement as involving“...choosing and formalising a set of ideas which are thought to be relevant to the problem solving activity in a specific context". Ideas meaning conceptions, how stakeholders interpret (sense-make) problem situations. Engagement is a process of first exposing stakeholders conceptions and then, through a process of reasoned debate and discussion, creatively finding new conceptions that provides a way to go forward all stakeholders. The final part of their engagement model is to ensure there is learning from the consequences of attempting to apply these conceptions to the 
problem situation. This may help the subsequent engagements (see also Houghton and Ledington, 2004).

At the heart of engagement is a social process of developing interpersonal relationships that helps to consolidate an agreement on an appropriate mindset. According to the social construction of reality doctrine (Gergen \& Gergen 2003), there are many social processes that revolve around the concept of language as constructing reality. In this instance, the Ledington and Ledington model is referring to the role of communication and discourse in the social construction of agreed conceptions. There is not thought to be a simple discourse social process, but discourse forms one of the many social processes that can work to help guide and shape. Conceptions are seen as articulations of value systems that are likely to be political, emotional and highly subjective.

Story-telling might be one way to reveal default conceptions in stakeholders (McLellan 2006); as a way of 'bootstrapping' conceptions. He suggests use of people reviewing other people's stories or description of the same problem situation. This helps in the understanding of how these different interpretations can still be reasonable. McLennan also makes the point that stories tend to force the teller to hold one view and justify their interpretation. In this sense, McLennan supports the position that conception forming occurs over many dimensions and can change over time. James and Minnis (2004) also argue that stories engage people emotionally, because they engage cognitively.

Stakeholder engagement might be thought of as an intense social capital building or as a networking exercise. Van Bueren, Klijn and Koppejan (2003) argue that collective action in problem solving be understood through a social network view of people's conceptions. The social network of conceptions is a way of understanding collective action. They argue that participants' conceptions are interdependent in the sense that the actions of certain people influence the conceptions of others. Understanding the actual process of how the participants, as a whole, conceptualise the problem is incredibly difficult. This is also because participants overlay the problem with conceptions around engaging in collective actions, introducing yet more conceptions. Quite often they are incommensurable.

\section{Recap}

All the above suggests an approach to interpreting messes. This alternative is to not to seek a one-off, upfront, unchanging conception of the mess followed by extensive analysis. Rather interpreting messes needs to be thought of as a process of continually seeking useful alternative conceptions. Engaging with this stream of conceptions rather than ignoring them 
is thought to be acknowledging what actually happens with messes. Resolving problems is about finding new conceptions of the mess, interpretations that dissolve the problem. But how does this happen in our day to day work life?

To make the argument of this paper more concrete, two case studies are now presented. In these, there was a significant shift in how the original mess was conceptualised which acted to dissolve (Ackoff, 1978) the problem as originally conceived and suggest a new way forward.

\section{Methodology}

The Anglo-American branch of epistemology searches for truths, typically using reasoning, explanation and empirics (Gray, 2003). The Continental Philosophers and the Pragmatists search for new meanings, interpretations or ways of seeing the world. These need to be justified to a sceptical audience (Rorty, 1989). This paper is aligned with the latter. It continues the task of attempting to justify the claim that messes need to be interpreted using a recursion of analysis and synthesis (shifting conceptions). This paper is focusing on synthesis,

The evidence in support of the paper's claim that interpreting messes can be seen to include a process of conception shifting is supported by the literature presented above and the two case studies that follow. The case studies are not interventions, rather one of the authors observed the discussions of key staff over time while working with the organisations. Case studies are understood to be a means of understanding structures and mechanism operating with the case (Walsham 1993:2006). One of these cases was an aid agency which had its conception of their situation shifted by a tragic event. The other case is a large rail corporation which shifted its conception because of an internal review. The structure and mechanisms behind these changes is explained.

The issue of generalisation often arises with case studies. The cases presented here are not intended to be samples (Tsang and Williams, 2007) but rather a means of emerging abstracting concepts by induction. Space only permits the presentation of the briefest of the case details. However, it is thought possible to justify the claim that in both cases there was a significant shift in conversation due to a shift in conceptions of the situation. How and why is explained.

\section{Case 1 - International Gospel Centre (IGC)}


The International Gospel Centre (IGC) is a not-for-profit aid organisation run out from Queensland's Sunshine Coast. Their mission is described in the corporate literature as 'Breaking poverty and bringing third world countries to Jesus'. The niche for IGC is their focus on providing spiritual as well as physical support for victims of poverty in third-world countries. IGC performs its main work through a child sponsorship program. Missionaries are sent to host nations to find children in urgent need of support. Sponsors are then sourced worldwide to fund these children. IGC is therefore involved in child education centres, emergency relief and other related aid programs.

The Manager, John Beard, contacted one of the authors and asked him to participate in a strategic expansion of IGC. Their strategy was defined as wanting to expand their operations by first gaining a lot more sponsorship. This conception of their strategy quickly headed into the problem that there was no money even to develop sponsorships: 'no money, no development'. Evidence of this conception can be seen in the words used in an appeal in IGC's newsletter:

IGC has very little room for development mainly because of the limited funds we have at our disposal. When money comes it has to go to the specified purpose it was allocated to... To gain more income we need more direct sponsorship, this would give us the opportunity to create a bigger base for admin work and therefore it would give us more options. John Beard

The conception they had of their situation was they were in a 'catch 22 ' situation. How do they generate sponsorship without money? This conception of their problem can be expressed graphically in the map below:

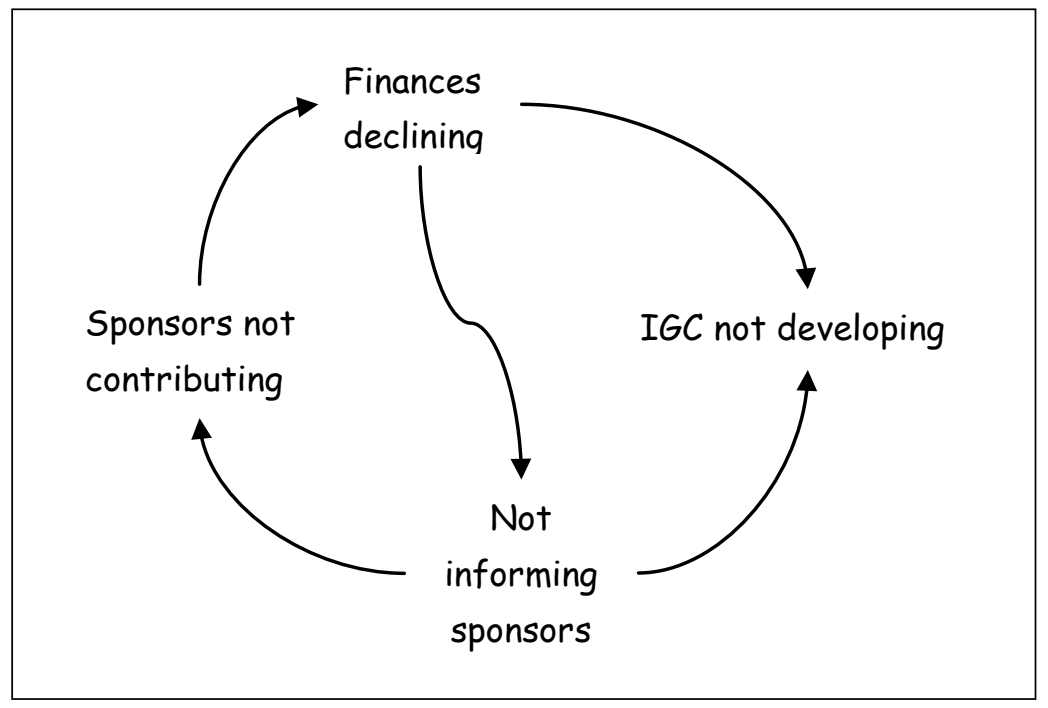


Having defined the problem, John Beard assumed the usual staircase theory of decision making and started the process of listing alternative solutions, intending to select one for evaluation and implementation. However the alternatives they could think of to solve their catch 22 were not creative. Historically a charismatic leader had been reasonably effective but since his parting they now mainly used the newsletter, and face to face appeals to church groups.

The way we get church group support is to do presentations using PowerPoints and just visiting churches around here and overseas. John Beard.

Presentations are done to connect a visual face to the project because without that people cannot make the link between us and the work we do. The face of the people in the presentations create a lasting image for would be sponsors to think about. Michelle, fieldworker.

However, getting sponsors to provide funding was a long and expensive process, one that IGC had almost exhausted. It involved extensive and expensive touring, public visits, organised overseas missions trips and so on. Attempts to consider how to re-conceptualise their problem raised the issue of not only how they appeal, but also what appealed most to their church audiences. An investigation was conducted in 1996, when John Beard assumed directorial responsibilities.

When I started at IGC I conducted extensive research to find out what attracted sponsors to IGC. I sent out a questionnaire and the responses we found indicated that our uniqueness [spiritual focus] which is in the essence of our message was the thing that attracted sponsors. John Beard.

He conceptualised a Christian focus but despite long discussions around other possibilities, the only viable action idea to emerge from this was to create a web site.

A website, with an attached church database, would give us a list of contacts that we need to further our cause. John Beard.

It was hoped the web site would enhance the organisation's spiritual mission and motivate potential sponsors. But they were not comfortable with this solution because they knew the power of the face to face conception to motivate sponsors. This meant that when exploring the web site idea particular face to face related issues started to be identified, For example, is a website simply a space on the web where people can visit? How do people get there? Why would they go? How can they be encouraged to take some interactive ownership of the site? 


\section{The event}

Before the web site was enacted in any detail, a tragic event intervened significantly changing IGC's conception of their problem. The event involved a child named 'Salvador'. His case made international news headlines. Salvador was a teenage boy who was asleep in his bed when his mentally unstable mother poured petrol over him and set him on fire. His injuries were so extensive and his physical condition was such that, when IGC stepped in to help by flying him to Australia for treatment, it drew significant international media attention to both Salvador and IGC. The manager John Beard was exposed to a great deal of media interest. As a result, numerous sponsors came forward asking to visit those in need. When they did they often became generous and committed sponsors. John Beard realised this reconceptualised his sponsorship problem.

Medical personnel have become involved in Western Australia for skin grafts and over there people in the media have run news stories on it and this has created for us a new possibility of seeing things. John Beard.

This re-conception immediately provided its own solutions. They merely needed to inform potential sponsor through media events of hard-luck stories and then encourage them to visit locations where IGC was working to meet with those suffering. From this, sponsorship looked after itself. This significantly changes John Beard's conception of what was IGC's problem and thus the alternative solutions include his comments to the web developer.

The reason we couldn't go forward with the website and other systems projects we wanted to is because since the development of the initial idea the organisation's donations have increased substantially. This has put us into a different framework than what we are used to. That project in particular showed us that we need to make our projects available to sponsors to visit and carry on in so they can see what's happening. This gives them something real and the results since that time have increased our sponsorship donations by $44 \%$. John Beard

Sponsors wanted to travel to see sufferers. The reality of encountering high levels of poverty left a lasting impression on them. In a phone interview, John Beard commented on what action ideas the new conception had emerged. 
Since gaining this exposure we have gained more [interest] but with that we have had to increase the amount of time we think about administrative problems so in another way we have created more work for ourselves ... double the work in fact. John Beard

He now saw the situation differently:

We noticed that the attention we were getting showed that our people overseas are simply not equipped for administration. Often, they are quite slow to react to people over here who expect better communication and things like that. The people are quite good at distributing the money but absolutely no good at administrating it. There have been many times where the money sent over is simply too hard to recover. We have tried through this experience to systemise IGC so that our records can be better managed. Our experience is that this leads to happy sponsors because more information is available. Salvador is just one of many examples of how these countries do not see the need for administration. John Beard

This new conception of their situation is shown diagrammatically below:

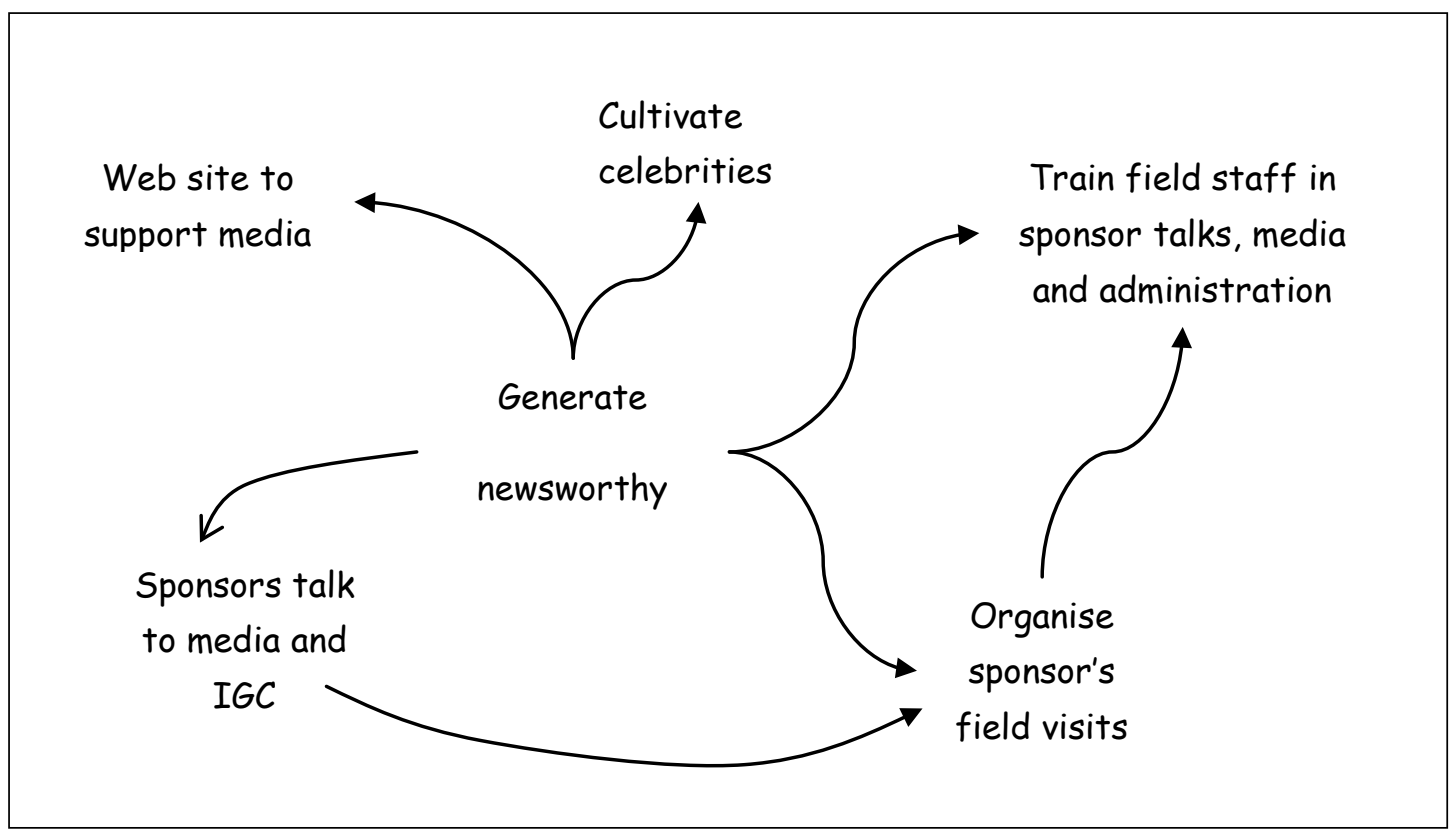

So in summary, the re-conceptualisation in this case was externally provided. This immediately suggested a different set of useful action ideas. With the benefit of hindsight, it can be sent that the old face to face conception was being extended to place the sponsors face to face with the children in need rather than John Beard. They had originally, accidently, put themselves between the sponsors and those in need. This may have been a legacy of 
the prior charismatic leader, a strength turning into blindness. It may have also been due their underestimating the rise of affordable charity tourism.

Salvador is now studying to be a medical doctor (after having had several operations on his back) and his progress is being tracked by IGC's corporate publications.

\section{Case 2}

RailCom is a pseudonym for an Australian railway company which is highly vertically integrated, with numerous depots servicing large distances in remote areas. There had been significant problems with both under and oversupply of materials through their internal supply chain. Senior managers initially defined the problem to be the lack of an information system that gave them an overview of the activities of the operations managers. They conceived of the need for a seamless, accountable, integrated, computerised internal supply management information system from raw material supplies to train customer, through engineering works and track maintenance operations. They were therefore attracted to the solution of implementing an enterprise wide computerised resource planning system (ERP). They choose SAP/ R3 which included the industry standard Supply Chain Operational Research (SCOR) model which offered the potential for optimising materials handing over the entire system. Evidence of this thinking comes from an interview with the General Manager:

I think our support mechanisms need to be radically re-jigged ... the R3 upgrade in 2004 is a big part of that as it provides us with large potential to tap into technology to improve [internal] supply chain management. General Manager

Their conception of the problem is represented in figure 3. 


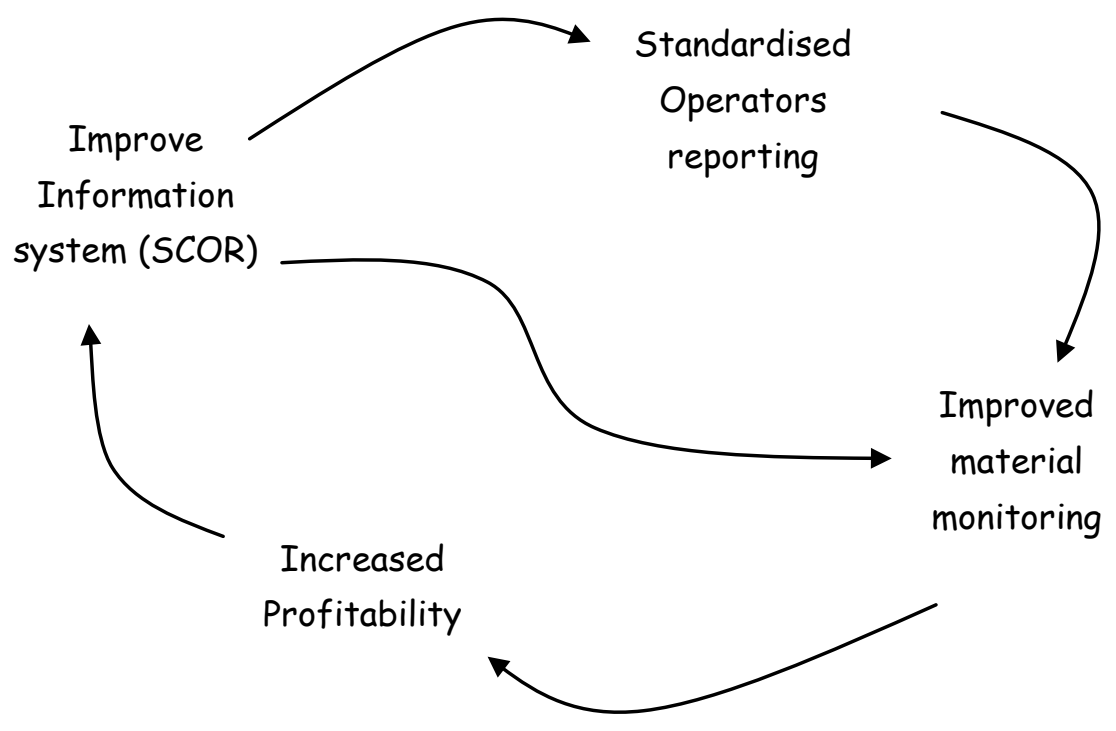

It was through attempts to implement this package and subsequent reviews of why it was not working, that the senior management started to appreciate that there was something going wrong with their conceptualisation of the situation. One of the authors was involved in some of these re-views. The remotely located operations managers did not seem to be complying with reporting requirements of the new system. The language used was that sufficient attention had been given to the 'social aspects' of information sharing systems. In an attempt to engage with the operations managers, they were interviewed as part of the engagement process, to find out why they were not using the ERP as required. A typical response was:

You need to contact people, they need to be reliable with regards to information. If a problem where urgent requirement for [product] comes in, if you do not have a contact they will not jump to your attention straight away and they do. - Commodity Facilitator

We interact with others; we certainly do not work alone. We rely on [Place A] to do some [production] work for us. We rely on [Place B] when we are short of people. We rely on the logistic group to advise us what [product] when to send it, who to send it to. So there is a bit of interaction. - Manager Inventory

I think those neurons will only sort of spark off when there is the receptor there that is going to get it. For example, I know what happened in the freight crew with the [product] supply out at the south. It was because of a couple of individuals, who through casual conversation almost, that I came in contact with, and I just was perhaps just waxing lyrical about you know, we should be able to be doing something better, 
because we were talking about, l'd been talking about an idea of having 40 foot containers, $\ldots$ and all sorts of ideas started to flow out of it a quite simple conversation, statement of ideas, all that sort of thing. - Operational Level

What came out of these conversations is the perceived need by the operations managers for engagement between themselves to get each others attention and for them to understand each others problems. Merely entering a written request or report onto the EPR was insufficient. Interpersonal contact was necessary to work around misconceptions. The operators were often dealing with non-routine requests.

This did not reflect an anti-technology culture. Given RailCom is an engineering company; staff were not shy of new technology. There was extensive use of technology but much of it was 'feral,' technology which bypassed the enterprise system often developed by the users. For example, the workaround spreadsheet complied from the diary mentioned below was not part the ERP but rather developed by the engineer to align with his needs.

... I rely heavily on a diary that tracks all material usage on a daily basis so it will have on there how many [of the product] we unloaded today so Bruce will come in write in the diary in what section, how many lengths of [product] he does. That diary then goes into a database internally within here and onto a spreadsheet ... - Construction Engineer

There was no perceived need to get this crucial information back into the main SAP system for corporate level knowledge management purposes.

Why not just use SAP for your records?

SAP ... doesn't have the functionality. With our three-way checking system the order is raised on SAP but it's only when the boys at [the station] acknowledge receipt for payment that it then goes into the SAP inventory system.

Most operational managers only revealed a very local conception of their roles in RailCom.

My role is to liaise between each structure and workshops as far as the commercial and contractual and I suppose internal agreement deliveries side of the supply [chain]. I also deal a little with supply, but not a great deal. - Contracts Administrator

Operations managers were asked what they thought worked well and what improvements they would like see enacted. A common thread was that workplace processes are almost designed not to work; so designing 'work arounds' was their job: 
But if you do not go and ring somebody and say it is important ... it may not happen and something critical may not happen ... That is where sometimes you need to shortcircuit the system to get a good understanding of each other's requirements and not be pig headed. - Project Officer

The result of the re-view (an engagement effort by senior managers) was an understanding that the operations managers were driven by a strong desire to engage meaningfully with each other, suppliers and clients, perhaps rather than with the senior managers. The operations managers needed written records of agreed transactions, but to get these enacted correctly, they also needed to understand and then influence the mindset of those involved, their conceptions of the transaction. The role of the technology was to back up these local engagements. The engagement generated common understandings. The process of engaging often resulted in previously unimagined solutions. Their day to day problem solving required more than the formal exchange of explicit, codified, asynchronous, data.

The response from senior management was to grow better engagement between themselves and operations managers by commissioning a corporate wide data model. This attempted to identify what information (data and intelligence) everyone including operations managers perceived they needed to make decisions as the basis of an organisational wide knowledge management system. It provided a mechanism for engaging with operations managers.

The following quote shows the change of heart from the General Manager:

... if you look at the IT revolution we focus on hardware, then software but the real issue is corporate or master data model, we never go there. ... We still struggle to know what business we are in ... So what we've got is a whole series of functional [silos] working along in some unconscious way where they still create value where they don't know how they do it and therefore we cannot agree on what is the big picture we are all working towards ... what are our agendas? So we mis-communicate on that level because we can't have a higher order to work towards.

He referred to "macro-processes" that went beyond rationalisation. Now the solution was:

To have better intellectual workers to help design better decision support type parameters built on the principles of lean manufacturing, logistics and process control 
and of course the data referencing ... we could then put our decision models over the top of those.

I don't think anybody understands anything about anyone's jobs.

\section{Technical services manager}

Further:

If our culture was such that we had the rigour to actually populate [SAP] with the information and the data and the insights we need then it might work. Culturally I don't think we are in a position to do that because it's a task that's far removed from the here and now ... - Technical Services.

The general manager also notes:

Nor do we have standard entered data or a corporate data model or data referencing so long before we can talk to each other we don't know what our units of measure are and if they are the same. We have a couple of key issues that we need to sort out structurally as a corporation. We might still have communication problems but the real issue to me is master data or the corporate data model. General Manager.

This new conception of what was required in mapped in figure 4.

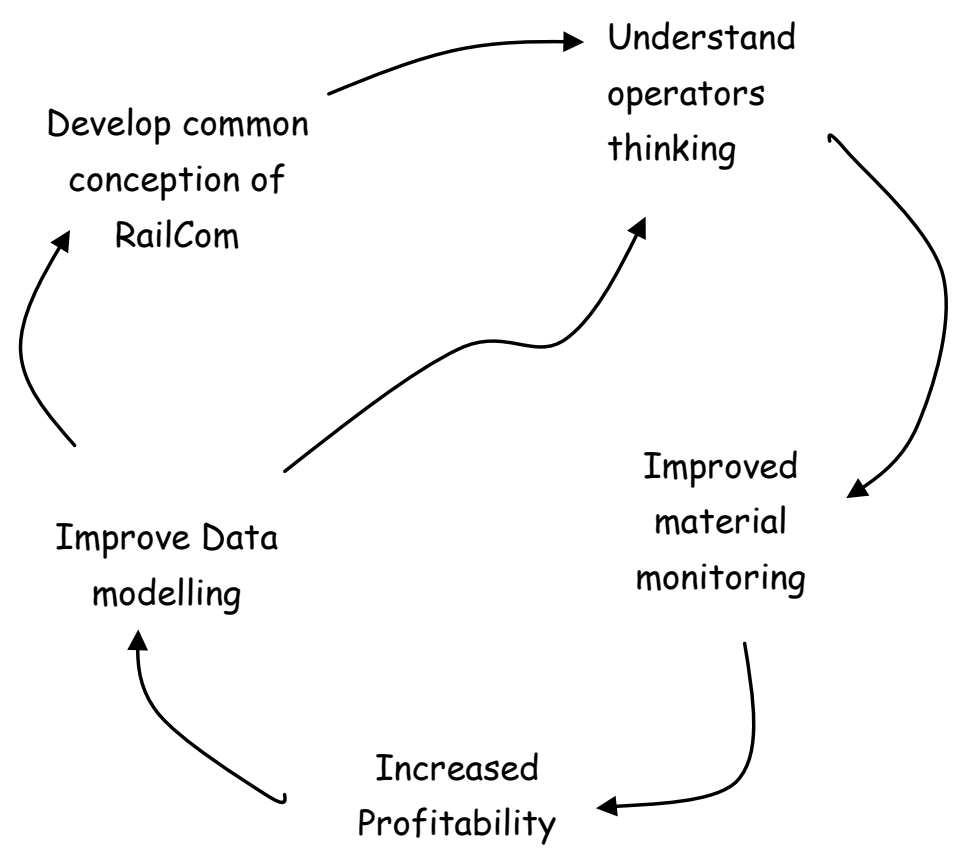


In this case, the reviews provided the re-conception of the problem; re-views should do that. Originally, the conception was of a lack of corporate information and decision making information systems. After the re-view the conception used was that operations managers engaging well with suppliers and clients but less so with senior management. The original conception suggested the solution of an ERP. The re-conception suggested a solution of using data modelling for an improved understanding of the decision making world of the operations managers. This analysis method can again be seen as an opportunity for generating new conceptions of the engagement of senior and operations managers.

\section{Conclusion}

This paper was an exploration of the proposition that interpreting messes involves seeking alternative conceptualization, synthesis. One source of these alternative conceptions involves metaphoric analysis. The mushroom rhizome, the shifting landscape, and the caterpillar were used to demonstrate a re-conception of messes. Each metaphor suggested an alternative solution set. The interest in synthesis came from John Dewey's rallying cry, synthesise don't just analyse. The 20th century has concentrated more on analysis than synthesis. Analysis is important but it needs to be in a conjoint relationship with synthesis. This includes the realisation that the act of analysis can serve the role of generating alternative conceptions. This is sometimes referred to as quantitative models generating qualitative models.

After explaining synthesis, and briefly discussing alternative methods for generating these new conceptions, the paper provided two case studies. These case studies described the mechanisms of shifting conceptions in two very different organisations. The first was a religious aid organisation. It had a massive re-conceptualisation forced on it, by the tragic burning of a child. This was a re-conceptualisation resulting from inter-stakeholder engagement. In this case it was first by noticing what got the media's attention and then by realizing donors wanted to travel and personally meet those in need. The second case involved a railway corporation. It re-conceptualised its mess by engaging with operations manager through a formal re-views. In both cases there was no mechanistic method used to re-conceptualising, such as a formal metaphoric or systems thinking analysis. However, it is thought these could work in other situations. The new conceptions in these two case studies came from stakeholders existing interpretation of the mess, interpretations not appreciated by the owners of the mess. 
The traditional stair case model of decision-making that suggests first defining the problem and then alternative solutions is seen as a significant understatement of how messes should be approached. Rather, a process of consistent reconceptualised is suggested, each new conception of the problem needs to be analysed. These newer conceptions lead to solutions almost unimaginable under the original conceptions of the mess.

\section{References}

Ackoff, R.L. (1978). The Art of Problem Solving: Accompanied by Ackoff's Fables, Wiley, USA.

Ackoff, R.L. (1994). From Mechanistic to Social Systems Thinking, Systems Thinking in Action Conference, USA.

Ackoff, R.L. (2000). 'Making a Difference: Systems Thinking/Systems Change', http://www.judgelink.org/presentations/Girlslink/ [Accessed August 2008].

Argyris C. \& Schon, D. (1996). Organisational Learning II: Theory, Method and Practice, Addison-Wesley, USA.

Chanin, M. \& Shapiro, H. (1985). Dialectical inquiry in strategic planning: Extending the boundaries, Acad Man Rev, 10: 663-675.

Checkland, P. (1981). Systems Thinking, Systems Practice, John Wiley, UK.

Checkland, P (1999). Soft Systems Methodology: A 30 Year Retrospective, John Wiley, UK.

Checkland, P (2005) Webs of Significance: The Work of Geoffrey Vickers, Systems Research and Behavioral Science, 22(4), p. 285.

Chia, R. (1996). Organisational Analysis as Deconstructive Practice, Walter de Gruyter, New York.

Churchman, C. W (1968). The Systems Approach, Dell Publishing Co., NY, USA.

Dewey, J. (1910). How We Think. NY: Dover.

Dooley, J. (1999). Problem-Solving as a Double-Loop Learning System, Adaptive Learning Design. Accessed: [August 2008], Online Resource: http://citeseer.ist.psu.edu/dooley99problemsolving.html 
Franco, L.A. (2006). Forms of conversation and problem structuring methods: A conceptual development', J Opl Res Soc, 57: 813.

Gergen, M. \& Gergen, K. (eds) (2003). Social Construction: A Reader, Sage, USA.

Gilbert, D.T. (1991). How mental systems believe, Am Psychol, 46: 107-119.

Gray J. (2003). Straw Dogs, Granta Books : London

Grint, K. (2003). Problems, problems, problems: The social construction of leadership, Hum Relat, 58: 1497-1494.

Houghton, L. (2008). Problem Solving through Cognitive Engagement, University of New England, Unpublished PhD Thesis.

Houghton, L. \& Ledington, P. (2004). The engagement approach to real world problem solving: toward a coherent soft systems based theoretical platform for real world problem solving, Sys Prac Act Res, 17: 497 -510.

James, C.H. \& Minnis, W.C. (2004). Organisational storytelling: It makes sense, Bus Horizons, 47(4): 23-32.

Klein, G. (1989) Sources of Power: How people make decisions. Boston: MIT Press.

Landry, M (1995) A note of the concept of 'Problem', Organization Studies, 16(2), pp.315344.

Ledington, P. \& Ledington, J. (2001). Interpretive inquiry: From comparison to engagement in SSM, 7th ANZSYS Conference, Edith Cowan University, Western Australia.

Liebl, F. (2002). The anatomy of complex societal problems and its implications for OR, J Opl Res Soc, 53: 161-184.

March, J.G. (1978). Bounded rationality, ambiguity and the engineering of choice, J Econ, 9: $587-608$.

March, J.G. (1988). Decisions and Organisations, Blackwell, NY, USA.

March, J.G. \& Simon, H.A. (1958). Organisations, John Wiley, NY, USA.

McFadzean E. \& Money, A. (1994). The Theory of Strategic Problem Solving, Henley Management College, Oxford. 
McLellan H. (2006). Corporate Storytelling Perspectives, The Journal for Quality and Participation, 29: 17-22.

Menand, L. (2001). The Metaphysical Club. London: Flamingo.

Mitroff I. I. (2004). William James and a Theory of Thinking, J of Information Technology Theory and Application, 6: 83-90.

Morgan, G. (1997). Images of Organisation, 2nd edn, SAGE, USA.

Newell, A. \& Simon, H.A. (1972). Human Problem Solving, Prentice Hall, NY, USA

O'Loughlin, A., McFadzean, E. (1999). Toward a holistic theory of strategic problem solving, Team Performance Management, 5: 103-120.

Peirce, C. S. (1878). How to Make Our Ideas Clear, Pop Sci Month, 12: 286-302.

Polya, G. (1962). Mathematical Discovery: On Understanding, Learning, and Teaching Problem Solving, Wiley, USA.

Polya, G. (1965). Mathematical Discovery, Vol. 2, Wiley, USA.

Rittel, H.W.J. \& Webber, M.M. (1973). Dilemmas in the general theory of planning, Policy Sci, 4:2, 155-169.

Rorty, R. (1989). Contingency, Irony and Solidarity. Cambridge: Cambridge University Press.

Rosenhead, J (1996) What's the problem? An Introduction to Problem Structuring Methods, Interfaces, 26(6), 117-131.

Schon, D. (1963). Displacement of Concepts, McGraw Hill, USA.

Schultz, M. \& Hatch, M.J. (1996). Living with multiple paradigms: The case of paradigm interplay in organizational culture studies, Acad Man Rev, 21: 529-557.

Simon, H.A. (1960). The New Science of Management Decision, Harper and Row, NY.

Simon H. A. (1996). Sciences of the artificial, MIT press: Mass. USA.

Simon, H.A. (1997). Administrative Behaviour: A Study of Decision Making Processes in Administrative Organisations, 4th edn, Free Press, NY, USA.

Simon, H.A. (2000). Public administration in today's world of organisations and markets, Political Science and Politics, 33: 749-756. 
Sleiss, D. (1986). In Search of Semiotics, Croom Helm, London.

Stacey, R. (1996). Management and the science of complexity: If organizational life is nonlinear, can business strategies prevail?, Res Technol Manage, 39: 8-10.

Stacey, R. (2001) Complex Responsive Process in Organisations: Learning and Knowledge Creation, Routledge, UK.

Stacey, R. (2003). Strategic Management and Organisational Dynamics: The Challenge of Complexity, 4th edn, Prentice Hall, UK.

Tucker, A.L., Edmondson, A.C. \& Spear, S. (2001) When problem solving prevents organisational learning, J Organ Change Manage, 15: 122.

Tsang E., \& Williams J. (2007) Generalization and Hume's Problem of Induction: Misconceptions and Clarifications, Social Sciences and Humanities Working Paper Series, Accessed: [August 2008], Online Resource: https://mercury.smu.edu.sg/rsrchpubupload/7853/InfoSysResearchSubmission.pdf

Ulrich, W. (2003) Beyond methodology choice: Critical systems thinking as critically systemic discourse, $\mathrm{J}$ of the Opl Res Soc, 54: 325-342.

Van Bueren, E.M., Klijn, E. \& Koppejan, J.F.M. (2003), Dealing with wicked problems in networks: Analyzing an environmental debate from a network perspective, J Pub Admin Res Theory, 13: 193.

Vickers, G. (1983) The Art of Judgement: A Study on Policy Making, Harper and Row, UK.

Walsham, G. (1995), Interpretive case studies in IS research: Nature and method, Euro J Inform Syst, 4:2, 74-81.

Walsham, G. (2006) Doing Interpretive Research, Euro J Inform Syst, 15: 320-330.

Weick, K. (1993) The Collapse of Sensemaking in Organizations: The Mann Gulch Disaster, Admin Sci Quart, 38: 628-652.

Weick, K. (1995) Sense making in Organisations, SAGE, USA.

Weick, K. (2001), Making Sense of the Organisation, Blackwell Business, Oxford UK.

Wheatley, M. (2001) Leadership and the New Science: Discovering Order in a Chaotic World, $2^{\text {nd }}$ Edition, Berrett-Koehler Publishers, USA. 


\section{Figures}

Figure 1 - IGC's initial situation conception map

Figure 2 - New Situation conception

Figure 3: Railcom initial situation conception

Figure 4 - RailCom's later situation conception 